\title{
Review of Jacked Up and Unjust: Pacific Islander Teens Confront Violent Legacies, by Katherine Irwin and Karen Umemoto
}

\author{
University of California Press, Oakland, California, 2016, 217 pp., \\ ISBN: 9780520283022
}

\author{
Review by Misty Harris \\ West Virginia University \\ Morgantown, West Virginia \\ USA \\ miharris1@mix.wvu.edu
}

From the first page of the introduction to Jacked Up and Unjust: Pacific Islander Teens Confront Violent Legacies, authors Katherine Irwin and Karen Umemoto put the experiences and voices of the Hawaiian youth in their study, front and center. Irwin and Umemoto open the book with the story of Angel, a sixteen-year old high school student known for a tough demeanor and ample fighting skills. In an ethnography about youth violence, leading with Angel's story sets Jacked Up and Unjust apart from most of the research studying youth violence. First, Angel is a young woman and research in youth violence (and beyond) often leaves out the voices of girls. Second, Angel is a Pacific Islander, a minority group underrepresented in research across fields. And finally, while Angel is from an urban Hawaiian high school and her and other urban students' unique experiences have much to offer other studies of urban youth and violence. Irwin and Umemoto weave Angel's story into that of Hawaiian boys and girls from both rural and urban neighborhoods. By including both male and female urban and rural youth in their study, Irwin and Umemoto challenge myths about rural crime and current research in youth violence that attribute teen violence to an adherence to codes of the (urban) street, focused on masculine identities and "middle-class status as a marker of success"

Specifically, Irwin and Umemoto address these traditional criminological explanations of youth violence as well as current themes in critical youth studies, and the punitive trends in both educational and juvenile justice institutions. Irwin and Umemoto build on the knowledge from these three areas to form their thesis of colonial patriarchy, which they define as "a system in which racial marginalization and male privilege are central organizing features of everyday life" (page 148). Using the lens of colonial patriarchy allows Irwin and Umemoto to investigate youth violence through the multiple and intersecting identities and realities the teens in their study face, including the impact of Hawaii's colonial past, racism, age, and gender and how these multiple oppressions work together to influence the lives of teens.

Angel's violent striking out in school had led to her referral, as it happened for the other youth introduced throughout the book, to a school program called the "lunch bunch", which provided "teens with food, cold drinks, and a nonjudgmental environment in which to talk about the challenges in their lives" (page 2). This is the setting of Irwin and Umemoto's ethnography, 
and they position themselves as supportive adults in the lives of the "lunch bunch" teens with an explicit recognition of the ways in which this population may be vulnerable to the intervention of adults. Between 2007 and 2015 one-hundred teens participated in the program, and Irwin and Umemoto interviewed forty-two of these youth in addition to twenty-one adults working in the schools, the juvenile justice system, and at various programs in the respective communities. As previously noted, the teens interviewed were from two high schools, one in a predominantly Native-Hawaiian, working class, rural community and another in a densely populated, diverse urban neighborhood. Irwin and Umemoto also held sixteen focus groups prior to undertaking the research, to allow the teens and their community members to define violence and "problems" as they viewed them. This concern for, and involvement of, the teens and communities further distinguish Jacked Up and Unjust from many ethnographic studies that define community and individual problems a prior and without input.

In Chapter 2 Irwin and Umemoto make explicit their methodologies and in so doing offer a best practices example of doing qualitative work with adolescents, making Jacked Up and Unjust a useful text for courses interested in youth violence, working with adolescents, or the art and science of ethnographic inquiry. The authors state: "While we wanted to gain an intimate knowledge of teens' worldviews and experiences, we did not want to compromise their safety, and this tension determined our roles as we interacted with teens" (page 5). Further, just as Irwin and Umemoto recognize their own positionality in their study they also focus on the intersectional positionality of the teens in in the macro structures of society. They begin by situating the teens' lives in the colonial history of Hawaii, while simultaneously viewing their experiences through the feminist theoretical lens of patriarchy.

Chapters 3 through 7 provide the results of the nine-year ethnography through the voices of the adolescents, and through the narratives of their lived experiences. Chapter 3 looks at the early home lives, or socialization, of girls and the struggles they faced, including taunting and teasing done primarily by boys, based on judgements about how well the girls fit into gender norms based on ideal images of white femininity. Irwin and Umemoto discover that girls are living under heavy domestic demands and describe the girls as "invisible laborers" (page 149). Chapter 4 explores the girls' struggle for respect as women, and their defense of "what was a respectable, upstanding, and honorable way of being in the world" (page 40). While there is a prolific body of work on masculinity norms that males struggle with, few studies fully consider the femininity norms that confront teen girls and how these are related to striking out. They also find that there is a fine line between the verbal and physical response to the challenges to girls' abilities to fit into these established gender expectations and norms, which were simultaneously constraining, complicated, and contradictory. The narratives of the girls made it clear that while they were completely aware of the injustices they faced in the domestic sphere because of their gender they were less aware of how their own judgements and condemnation of other girls shaped their experiences.

The boys' narratives similarly revealed that they were aware of their own oppression, but while gender remained salient, the racialization of native Pacific Islander boys within the context 
of colonialization became central. The text crescendos in this chapter as the boys' themselves express the impact of a "jacked up" colonial system that has placed them in a hierarchy they fully aware of and actively resist. Irwin and Umemoto did not find a single code that the boys in their studies lived by, but instead found that boys had rather individual notions of right and wrong, often defined by individual notions of what was right and wrong that was at times in conflict with other boys' ideas about the same. What is more, Irwin and Umemoto demonstrate how these ideas of what are right and wrong were often influenced by traditional American notions of civic duty and masculine responsibilities. Irwin and Umemoto uncovered important ways in which gender constrained all the teens, and how the differences in the ways gender constrained teens translated into their transitions into adulthood, and the world beyond high school. While the heavy domestic demands on girls had long introduced then to the responsibilities of adulthood, boys were less prepared for how they would perceive and fulfill masculine identities in a world that offered limited pathways for minority youth. In addition to exploring the outcomes of youth transitions into adulthood, Irwin and Umemoto also demonstrate how compassionate adults that teens encounter in the school, juvenile justice system, and community can make a difference.

Irwin and Umemoto leave the reader with a foray into proposed compassionate and constructive policies and practices that might realign the needs of students with the response from adults, schools, communities, and the juvenile justice system. Irwin and Umemoto demonstrate how zero-tolerance policies in schools and the juvenile justice systems have not only not done what they intended - deterrence through threat of punishment - but had instead had an unequal impact on the institutionalization of minority youth in Hawaii and beyond. Irwin and Umemoto challenge the "tone deafness on the part of policy makers as well as the public about these youth [which] increases the neglect and injustice they face" (page 176). They ask for nothing short of a full change in basic assumptions undergirding how research, policy, and practice think about and respond to youth violence, juxtaposing harsh "zero-tolerance" policies with the compassionate adults within institutions that exercise their discretion to guide teens in their own growth and development. In doing so, they not only point out efforts in the direction of restorative justice in other nations, including Canada and Australia, but they also introduce the reader to a native Hawaiian approach called ho'oponopono, defined as "setting to right; to make right; to correct; to restore and maintain good relationships among family, and family-andsupernatural powers" (page 166).

Irwin and Umemoto demonstrate how various community organizations in Hawaii use ho'oponopono to address the multiple oppressions that have shaped the lives of the teens and their communities. While ho'oponopono provides a specific example in the context of Hawaii, it encourages the seeking out of alternative approaches to justice and individual and community restoration that is culturally appropriate and indigenously informed. This goes beyond suggesting replicative general restorative justice approaches with little or no acknowledgement of the specific and nuanced histories and biographies that intersect to shape and define the oppressions experienced by specific people and their reactions to them. Ultimately, Jacked Up and Unjust offer insight for the fields of youth violence, critical youth studies, and policies and practices 
addressing punishment in schools and the juvenile justice system, while providing an invaluable read for anyone endeavoring to undertake a school-based, or adolescent-focused ethnography. 